\title{
PROTOTYPE SISTEM KENDALI KADAR KEPEKATAN ASAP PADA SMOKING ROOM DENGAN METODE FUZZY LOGIC BERBASIS ARDUINO
}

\author{
${ }_{1,2,3}$ Pendidikan Vokasional Teknik Elektro, Fakultas Teknik, Universitas Negeri Jakarta
Venan Ishfahani, ${ }^{2}$ Nur Hanifah Yuninda, ${ }^{3}$ Purwanto Gendroyono \\ Email : sunanishfahani146@gmail.com
}

\begin{abstract}
The purpose of this research is to make prototype of smoke concentration levels control system in smoking room by fuzzy logic method based on arduino. The prototype is able to detect and control the smoke to stay constantly in allowed threshold to the smoking room and provide periodic information about the concentration level in that smoking room automatically. This research uses Research and Development Method, which includes requirements analysis, design, basic implementation into prototype form. Requirements analysis is based on the lack of smoke detection and control systems in smoking rooms. The design of the control system in this study is applied to fuzzy logic controller. This research emphasizes more on the basic implementation of the desired prototype by standards testing such as output voltage testing and fuzzyfication testing that have not arrived at the stage of efficiency testing. The results show that the system will be put into danger condition if the concentration of smoke reaches 80 PPM. At that level, the voltage measured by the sensor is in the range of 3.19 to $3.41 \mathrm{VDC}$ with an average voltage increase of 0.035 to $0.04 \mathrm{VDC}$ per PPM. Error in fuzzyfication testing is $0.04 \%$ and $0.08 \%$ based on calculation.
\end{abstract}

Keywords: Control System, Smoke, DC Fan, Smoking Room, Fuzzy Logic

\begin{abstract}
Abstrak
Tujuan penelitian ini adalah membuat prototype sistem kendali kadar kepekatan asap pada smoking room dengan metode fuzzy logic berbasis arduino. Alat ini dapat mendeteksi dan mengendalikan asap agar tetap pada ambang batas yang diperbolehkan pada smoking room serta memberikan informasi secara periodik tentang kadar kepekatan asap yang terdapat pada smoking room secara otomatis. Penelitian ini menggunakan Metode Penelitian dan Pengembangan (Research and Development) yang meliputi analisis kebutuhan, perancangan, implementasi dasar dalam bentuk prototype dan pengujian. Analisis kebutuhan didasari karena jarang terdapatnya sistem deteksi dan kendali asap pada smoking room. Perancangan sistem kendali pada penelitian ini diterapkan fuzzy logic controller. Penelitian ini lebih menekankan pada implementasi dasar dari prototype yang diinginkan dengan pengujian standar seperti pengujian tegangan keluaran dan pengujian fuzzyfikasi yang belum sampai pada tahap pengujian efisiensi. Hasil penelitian menunjukkan bahwa sistem akan mengindikasikan sebuah bahaya jika kadar kepekatan asap mencapai 80 PPM. Pada kadar tersebut, tegangan yang terukur oleh sensor berada pada kisaran 3,19 sampai 3,41 VDC dengan rata-rata kenaikan tegangan sebesar 0,035 sampai 0,04 VDC per PPM. Error pada pengujian fuzzyfikasi adalah sebesar 0,04 \% dan $0,08 \%$ yang didasarkan pada perhitungan.

Kata kunci: Sistem Kendali, Asap, Kipas DC, Ruangan Merokok, Logika Fuzzy
\end{abstract}

\section{PENDAHULUAN}

Seiring dengan perkembangan ilmu pengetahuan dan teknologi, sistem kendali semakin berperan penting dalam kehidupan sehari-hari. Sistem kendali berperan dalam berbagai sektor seperti industri, perkantoran, rumah tangga dan lain-lain. Salah satunya dalam hal sistem kendali kadar kepekatan asap rokok. Ketika seseorang merokok, asapnya akan mencemari lingkungan sekitar, udara dalam ruangan dan memberikan dampak buruk bagi kesehatan. Perokok mengetahui dengan baik dampak yang akan terjadi akibat merokok, tetapi hal tersebut tidak memberikan mereka kesadaran untuk berhenti merokok. Padahal, meskipun seseorang tidak secara langsung merokok, hanya menghirup asap rokok orang lain saja secara signifikan juga dapat meningkatkan resiko kesehatan seperti halnya gangguan pernafasan, asma, kanker paru-paru, tumor dan sebagainya. Hal ini membuktikan betapa bahayanya asap rokok yang kita hirup dimanapun kita berada. Oleh karena itu diperlukan sebuat tempat khusus untuk mengurangi pencemaran asap rokok yaitu smoking room.

Smoking room ditujukan untuk mengurangi pencemaran udara di lingkungan sekitar dan mencegah efek bahaya asap rokok pada perokok khususnya perokok pasif. Smoking room selalu dicemari asap rokok yang pekat. Mengingat campuran kandungan asap rokok yang terdiri 
dari zat-zat berbahaya seperti Nikotin, Karbon Monoksida, Timah Hitam, Amoniak, Hidrogen Sianida dan Tar. Smoking room harus memiliki standar ukuran yang sesuai dengan sirkulasi udara yang baik. Standar ukuran minimum smoking room menurut PT. Djarum adalah 1 meter/orang. Sirkulasi udara yang berkaitan dengan ambang batas kadar asap rokok di dalam smoking room menurut WHO (World Health Organization) adalah sebesar $0,025 \mathrm{PPM} / \mathrm{m}^{3}$. Menurut penelitian Talumewo, et al. (2016) menyatakan bahwa pada saat kadar CO kurang dari 80 Part Per Million (PPM), maka kipas DC (Direct Current) belum bekerja, setelah kadar CO lebih dari 80 PPM maka kipas $D C$ akan berputar untuk menyedot asap rokok. Hal ini membuktikan bahwa kadar CO 80 PPM sangat membahayakan bagi kesehatan.

Penelitian tersebut belum menerapkan metode fuzzy logic sehingga timbulnya asap langsung dideteksi sebagai tingkat bahaya yang seragam. Kenyataannya, jumlah asap yang dihasilkan harus dikombinasikan dengan konsep kecerdasan buatan agar tingkat bahaya dapat diatur sehingga menghasilkan keputusan yang akurat untuk tindakan selanjutnya. Perokok yang berada di dalam smoking room biasanya menyalakan kipas (exhaust fan) secara manual untuk mengurangi kadar kepekatan asapnya. Tentu saja cara ini dianggap kurang praktis. Maka dari itu, peneliti membuat prototype sistem kendali kadar kepekatan asap pada smoking room dengan metode fuzzy logic berbasis arduino. Sistem kendali akan mendeteksi kadar kepekatan asap melalui sensor MQ2 disertai dengan perubahan $P P M$-nya $(\triangle P P M)$ seiring waktu. Output sistem kendali ini berupa kipas $D C$ yang akan menyala otomatis dengan kecepatan putar kipas yang beragam berdasarkan kadar kepekatan asap yang dideteksi untuk mengurangi kepekatan asap pada smoking room secara terus-menerus. Apabila kadar kepekatan asap melebihi 80 PPM, maka $L C D$ akan memberikan peringatan untuk segera keluar dari ruangan serta buzzer menyala.

\section{METODE}

Metode penelitian yang digunakan pada penelitian ini adalah Metode Penelitian dan Pengembangan (Research and Development) yang meliputi analisis kebutuhan, perancangan, implementasi dasar dalam bentuk prototype dan pengujian. Analisis kebutuhan didasari karena jarang terdapatnya sistem deteksi dan kendali asap pada smoking room. Perancangan sistem kendali pada penelitian ini diterapkan fuzzy logic controller. Penelitian ini lebih menekankan pada implementasi dasar dari prototype yang diinginkan dengan pengujian standar seperti pengujian tegangan keluaran dan pengujian fuzzyfikasi yang belum sampai pada tahap pengujian efisiensi.

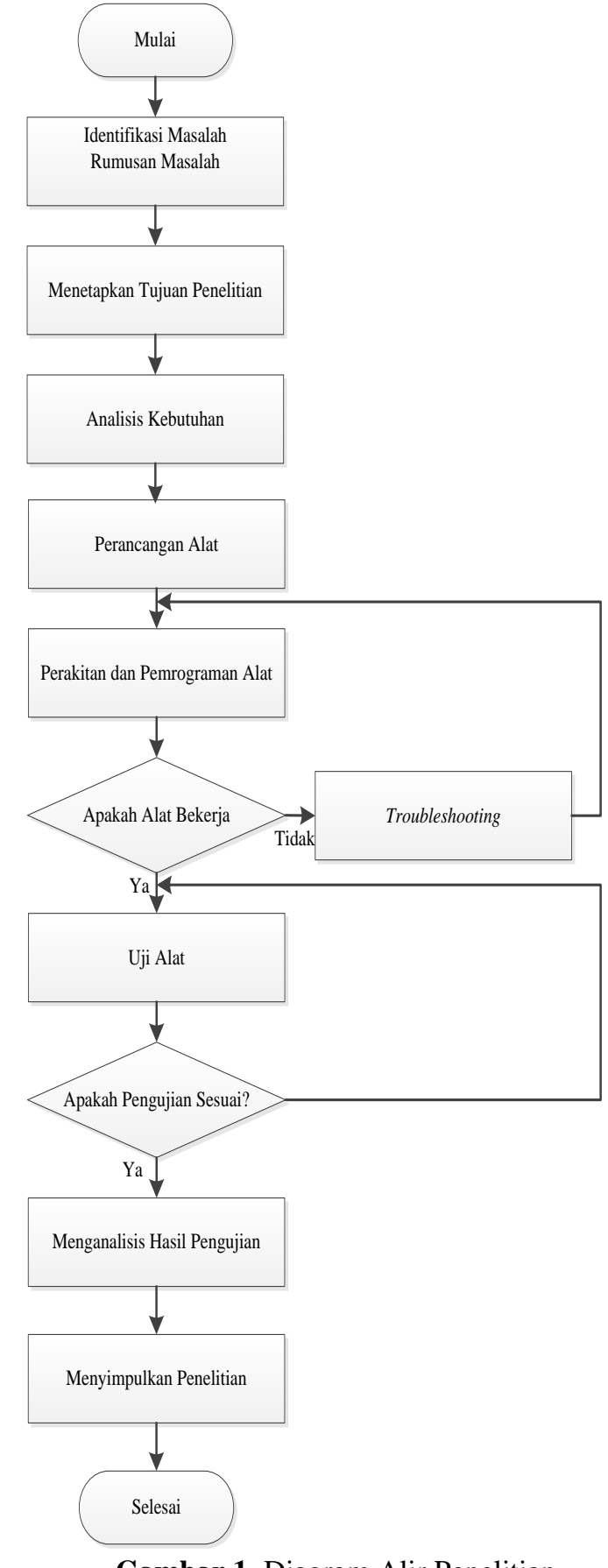

Gambar 1. Diagram Alir Penelitian 
Penelitian ini bertujuan membuat prototype sistem kendali kadar kepekatan asap pada smoking room dengan menggunakan metode fuzzy logic berbasis arduino. Sistem kendali ini terdiri dari beberapa komponen elektronika antara lain adalah power supply $12 \mathrm{VDC}$, arduino UNO R3, sensor MQ2, kipas $D C, L C D$ 20x4, buzzer dan komponen pelengkap lainnya. Diagram blok kerangka berpikir ditunjukkan pada gambar 2.

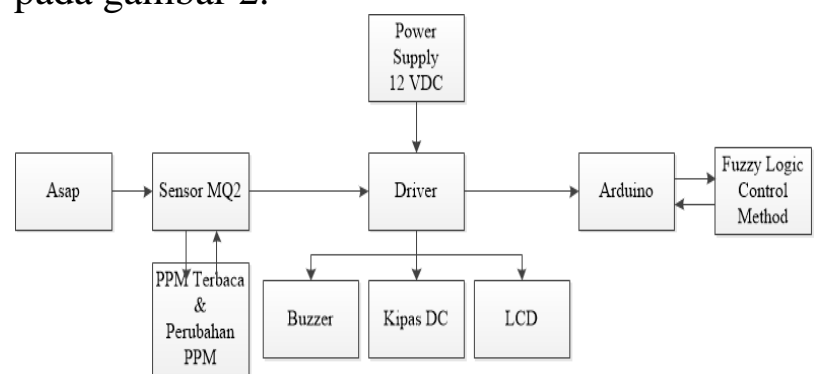

Gambar 2. Diagram Blok Kerangka Berpikir

Sistem akan mengendalikan kadar kepekatan asap pada smoking room dengan mengaktifkan kipas $D C$ secara otomatis yang akan mengendalikan (menyedot asap) sehingga akan mengurangi kadar kepekatan asap pada smoking room. Inti processing dari sistem kendali ini adalah arduino yang diprogram dengan bahasa $\mathrm{C}$ sebagai processing dari fuzzy logic agar dapat mengendalikan perangkat yang terhubung. Sistem akan aktif ketika diberikan power supply 5 VDC pada arduino dan 12 VDC pada kipas $D C$. Sensor MQ2 membaca kadar kepekatan asap yang terdapat pada smoking room. LCD 20x4 akan menampilkan kadar kepekatan asap dan warning system setelah diproses Arduino. Buzzer aktif sebagai alarm ketika kadar kepekatan asap ditingkat yang berbahaya. Input system diproses menggunakan metode fuzzy logic pada arduino.

Ketika sensor MQ2 mendeteksi asap dalam jumlah tertentu (PPM), maka arduino memproses berdasarkan metode fuzzy logic dengan beberapa tahap. Dimulai dari mem-fuzzyfikasi-kan nilai inputan dari nilai crisp-nya menjadi variabel fuzzy sehingga didapatkan derajat keanggotaannya. Kemudian menentukan aturan fuzzy-nya untuk mendefuzzyfikasi-kannya dengan cara mengagregasi nilai fuzzy sehingga didapatkan nilai output-nya yaitu kipas $D C$ yang dapat mengatur kecepatannya. Pada kadar kepekatan tertentu, kipas $D C$ tersebut akan berputar dengan tingkat tertentu. Selama pembacaan kadar kepekatan asap oleh sensor, LCD 20x4 menampilkan perubahan kadar kepekatan asap (dalam $P P M$ ) serta kecepatan kipasnya (dalam \%). Kipas $D C$ dapat mengatur kecepatannya secara otomatis menjadi 3 speed yaitu speed low, speed medium, speed high. Pada kadar kepekatan asap yang melebihi ambang batas, sistem akan memberikan peringatan berupa buzzer aktif dan $L C D$ 20x4 menampilkan tulisan "KELUAR DARI RUANGAN!

Alat dan bahan yang dibutuhkan pada penelitian ini antara lain: Arduino UNO R3, sensor MQ2, LCD 20X4, kipas DC, driver control, bor listrik, obeng, tang, transistor TIP41C, dioda IN4004, kapasitor 2A4J10, kabel jumper dan akrilik. Mekanik alat didesain seperti bentuk kultur smoking room berbentuk ruangan persegi panjang berdimensi balok menggunakan akrilik. Mekanik alat disesuaikan dengan penggunaan komponen elektronika seperti sensor dan lainnya. Mekanik alat dirancang menggunakan skala 1:20 berdasarkan ukuran smoking room asli dengan ukuran panjang 6 meter, lebar 4 meter, tinggi 3 meter sehingga dibuat menjadi panjang $30 \mathrm{~cm} \times 20 \mathrm{~cm}$, tinggi $15 \mathrm{~cm}$ seperti terdapat pada gambar 3 .

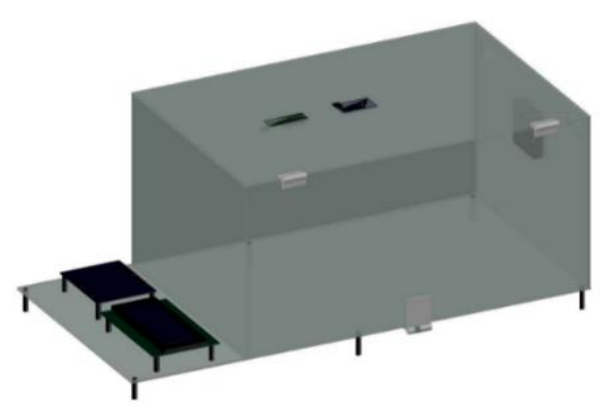

Gambar 3. Desain Alat Tampak Samping

Input system terdiri dari sebuah sensor yaitu sensor MQ2 yang berfungsi untuk mendeteksi asap. Setelah didapatkan nilai parameter input, dilakukan proses kendali oleh Arduino. Di dalamnya terdapat proses kendali metode fuzzy logic dengan teknik agregasi yang sudah ditentukan program Arduino dan dilengkapi dengan driver control-nya. Setelah melalui proses kendali, maka dihasilkan output system berupa kecepatan kipas $D C, L C D$ dan buzzer.

Sistem pengendalian pada alat ini bekerja berdasarkan metode fuzzy logic. Pada pengendalian putaran kipas, terdapat input untuk mengetahui kadar kepekatan asap dan $\triangle P P M$. Input-an dilanjutkan ke dalam proses fuzzy. Input-an inilah yang akan di-fuzzyfikasi-kan ke himpunan fuzzy dan menjadi fungsi keanggotaan fuzzy. Sensor MQ2 yang mendeteksi kadar kepekatan asap di-fuzzyfikasi-kan berdasarkan himpunan keanggotaannya mengikuti perubahan $P P M$-nya. Kemudian dilakukan proses penalaran berdasarkan rule base system menggunakan operator MAX-MIN sesuai metode FIS MAMDANI. Selanjutnya mendefuzzyfikasi-kan dengan metode center of sum 
untuk mendapatkan hasil kecepatan kipas putar (dalam \%)

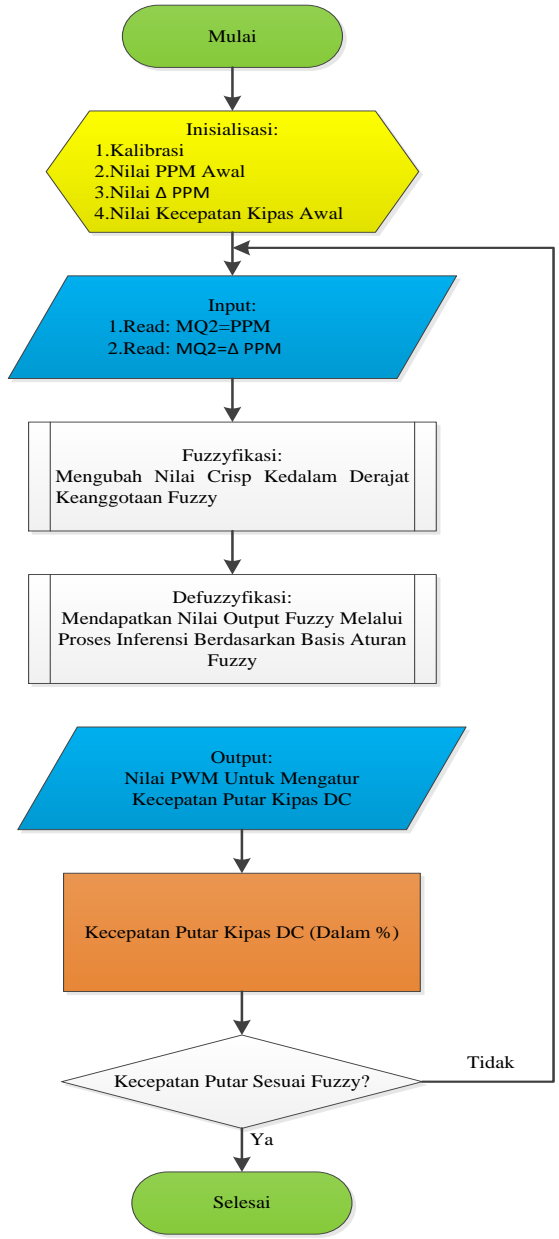

Gambar 4. Flowchart Utama Alat

Teknik dan prosedur pengumpulan data yang digunakan pada penelitian ini sebagai berikut:

1. Analisis kebutuhan yang dibutuhkan pada pembuatan prototype ini.

2. Merancang alat, membuat mekanik alat dan memprogram prototype sistem kendali kadar kepekatan asap dengan metode fuzzy logic berbasis arduino berbahasa $\mathrm{C}$.

3. Mensimulasikan sistem kendali dengan hardware serta melakukan instalasi software.

4. Melakukan eksperimen pengujian hardware dan software terhadap sistem kendali.

5. Mengambil data hasil pengujian hardware dan software dan menganalisisnya.

6. Mengambil kesimpulan hasil penelitian dari analisis data yang diperoleh dari pengujian sistem

\section{HASIL DAN PEMBAHASAN}

Hasil pengujian alat ini terdiri dari 2 yaitu pengujian tegangan dan pengujian fuzzyfikasi. Pengujian Pengujian tegangan output sensor MQ2 ini berguna untuk mengetahui perubahan tegangan output sensor terhadap perubahan nilai
$P P M$ yang dibaca oleh sensor MQ2. Pengujian percobaan pertama dan kedua terdapat pada tabel 1 dan 2. Pengujian percobaan pertama dilakukan ketika sistem benar-benar baru diaktifkan, sementara pengujian percobaan kedua dilakukan ketika sistem sudah diaktifkan dan digunakan secara berkala. Pengujian ini dilakukan di ruangan ber- $A C$ dengan pengaturan suhu $16{ }^{\circ} \mathrm{C}$. Ukuran ruangan sebesar 3 meter $\mathrm{x}$ 2,5 meter. Demi memacu kenaikan PPM, digunakan rokok yang ditambahkan seiring waktu dari 1 batang rokok sampai dengan 3 batang rokok yang dibakar dan diletakkan di dalam miniatur smoking room.

Tabel 1. Hasil Pengujian Tegangan Output Sensor MQ2

\begin{tabular}{ccc}
\multicolumn{3}{c}{$($ Percobaan 1) } \\
\hline No & $(P P M)$ & Teg. Terukur $(V D C)$ \\
\hline 1 & 0 & 2,31 \\
2 & 5 & 2,55 \\
3 & 8 & 2,65 \\
4 & 10 & 2,68 \\
5 & 15 & 2,77 \\
6 & 19 & 2,86 \\
7 & 22 & 2,91 \\
8 & 27 & 2,92 \\
9 & 35 & 2,99 \\
10 & 40 & 3,01 \\
11 & 44 & 3,04 \\
12 & 53 & 3,1 \\
13 & 56 & 3,11 \\
14 & 61 & 3,12 \\
15 & 68 & 3,14 \\
16 & 71 & 3,15 \\
17 & 79 & 3,16 \\
18 & 82 & 3,19 \\
19 & 90 & 3,2 \\
20 & 93 & 3,22
\end{tabular}

Tabel 2. Hasil Pengujian Tegangan Output Sensor MQ2

\begin{tabular}{ccc}
\multicolumn{3}{c}{$($ Percobaan 2$)$} \\
\hline No & $(P P M)$ & Teg. Terukur $(V D C)$ \\
\hline 1 & 0 & 2,66 \\
2 & 5 & 2,84 \\
3 & 8 & 2,90 \\
4 & 10 & 3,07 \\
5 & 15 & 3,09 \\
6 & 19 & 3,12 \\
7 & 22 & 3,15 \\
8 & 27 & 3,20 \\
9 & 35 & 3,21 \\
10 & 40 & 3,23 \\
11 & 44 & 3,24 \\
12 & 53 & 3,25 \\
13 & 56 & 3,28 \\
14 & 61 & 3,29 \\
15 & 68 & 3,31 \\
16 & 71 & 3,34 \\
17 & 79 & 3,35
\end{tabular}




\begin{tabular}{rrr}
18 & 82 & 3,36 \\
19 & 90 & 3,41 \\
20 & 93 & 3,44 \\
\hline
\end{tabular}

Pada pengujian software ini, dibandingkan antara hasil defuzzyfikasi sistem yang ditampilkan pada $L C D$ dengan defuzzyfikasi menggunakan perhitungan manual. Pembuktian perhitungan dan analisanya terdapat setelah tabel 4.

Pada pengujian software ini, dilakukan pengujian fuzzyfikasi pada saat $P P M$ naik dan turun. Berdasarkan hasil pengujian yang terdapat pada tabel 3, 4 dan gambar 8, 9, dapat disimpulkan bahwa pada saat $P P M$-nya naik, maka kecepatan putar kipas akan naik, sedangkan pada saat $P P M$-nya turun, maka kecepatan putar kipas akan turun. Kipas terus bekerja berdasarkan fuzzy logic control method untuk mengendalikan PPM supaya tetap pada ambang batas yang diperbolehkan sistem yaitu 80 PPM. Berdasarkan hasil pembacaan pada $L C D$, nilai fuzzy dari kecepatan putar kipas ditampilkan dalam bilangan desimal dengan pembulatan 5 ke bawah dan 5 ke atas. Apabila dibandingkan dengan perhitungan manual, maka akan terdapat nilai error-nya. Hal ini disebabkan karena pada perhitungan manual, nilainya riil dan bulat dengan beberapa angka di belakang koma. Rata-rata error hasil pengujian software ini adalah $0,04 \%$ pada pengujian fuzzy naik dan $0,08 \%$ pada pengujian fuzzy turun.

Tabel 3. Hasil Pengujian Fuzzy Naik

\begin{tabular}{|c|c|c|c|c|c|c|c|}
\hline \multirow[b]{2}{*}{ No. } & \multirow{2}{*}{$\begin{array}{l}\text { Jumlah } \\
\text { Rokok } \\
\text { (Batang) }\end{array}$} & \multirow{2}{*}{$\begin{array}{c}\text { Waktu } \\
\text { Menit } \\
\text { Ke- }\end{array}$} & \multirow{2}{*}{$\begin{array}{c}\text { PPM } \\
\text { LCD } \\
(\mathrm{PPM})\end{array}$} & \multirow{2}{*}{$\begin{array}{l}\triangle \mathrm{PPM} \\
\mathrm{LCD} \\
(\mathrm{PPM})\end{array}$} & \multicolumn{3}{|c|}{ Kecepatan Kipas } \\
\hline & & & & & $\begin{array}{c}\text { LCD } \\
(\%)\end{array}$ & $\begin{array}{l}\text { Hitung } \\
(\%)\end{array}$ & $\begin{array}{c}\text { Error } \\
(\%)\end{array}$ \\
\hline 1 & 1 & $0-2$ & & 3 & 10 & 10 & 0 \\
\hline 2 & 1 & $2-4$ & 10 & 5 & 10 & 10 & 0 \\
\hline 3 & 1 & $4-6$ & & 7 & 29,95 & 30 & 0,17 \\
\hline 4 & 1 & $6-8$ & & 3 & 34,65 & 34,69 & 0,12 \\
\hline 5 & 1 & $8-10$ & 25 & 5 & 30 & 30 & 0 \\
\hline 6 & $1-2$ & $10-12$ & & 7 & 34,70 & 34,69 & 0,03 \\
\hline 7 & $1-2$ & $12-14$ & & 3 & 34,75 & 34,69 & 0,17 \\
\hline 8 & $1-2$ & $14-16$ & 45 & 5 & 50 & 50 & 0 \\
\hline 9 & $1-2$ & $16-18$ & & 7 & 65,30 & 65,31 & 0,02 \\
\hline 10 & $1-2$ & $18-20$ & 65 & 3 & 65,30 & 65,31 & 0,02 \\
\hline 11 & $2-3$ & $20-22$ & & 5 & 70 & 70 & 0 \\
\hline 12 & $2-3$ & $22-24$ & & 7 & 65,35 & 65,31 & 0,06 \\
\hline 13 & $2-3$ & $24-26$ & & 3 & 65,30 & 65,31 & 0,05 \\
\hline 14 & $2-3$ & $26-28$ & 85 & 5 & 90 & 90 & 0 \\
\hline 15 & 3 & $28-30$ & & 7 & 85 & 85 & 0 \\
\hline 16 & 3 & $30+$ & & 3 & 90 & 90 & 0 \\
\hline 17 & 3 & $30+$ & 100 & 5 & 90 & 90 & 0 \\
\hline 18 & 3 & $30+$ & & 7 & 90 & 90 & 0 \\
\hline
\end{tabular}

Tabel 4. Hasil Pengujian Fuzzy Turun

\begin{tabular}{cccccccr}
\hline \multicolumn{3}{c}{ Jumlah } & Waktu & PPM & $\Delta$ PPM & \multicolumn{3}{c}{ Kecepatan Kipas } \\
No. & $\begin{array}{c}\text { Rokok } \\
\text { (Batang) }\end{array}$ & $\begin{array}{c}\text { Menit } \\
\text { Ke- }\end{array}$ & $\begin{array}{c}\text { LCD } \\
(\text { PPM })\end{array}$ & $\begin{array}{c}\text { LCD } \\
(\text { PPM })\end{array}$ & $\begin{array}{c}\text { LCD } \\
(\%)\end{array}$ & $\begin{array}{c}\text { Hitung } \\
(\%)\end{array}$ & $\begin{array}{c}\text { Error } \\
(\%)\end{array}$ \\
\hline 1 & 3 & $0-2$ & & 7 & 90 & 90 & 0 \\
2 & 3 & $2-4$ & \multirow{2}{*}{100} & 5 & 90 & 90 & 0 \\
3 & 3 & $4-6$ & & 3 & 89,95 & 90 & 0,06 \\
4 & 3 & $6-8$ & \multirow{2}{*}{85} & 7 & 85 & 85 & 0 \\
5 & $2-3$ & $8-10$ & & 5 & 89,95 & 90 & 0,11 \\
\hline
\end{tabular}

\begin{tabular}{cccccccr}
\hline 6 & $2-3$ & $10-12$ & & 3 & 65 & 65,31 & 0,47 \\
7 & $2-3$ & $12-14$ & & 7 & 65 & 65,31 & 0,47 \\
8 & $2-3$ & $14-16$ & 65 & 5 & 70 & 70 & 0 \\
9 & $1-2$ & $16-18$ & & 3 & 65,30 & 65,31 & 0,02 \\
10 & $1-2$ & $18-20$ & 45 & 7 & 65,25 & 65,31 & 0,09 \\
11 & $1-2$ & $20-22$ & & 5 & 50 & 50 & 0 \\
12 & $1-2$ & $22-24$ & & 3 & 34,70 & 34,69 & 0,03 \\
13 & $1-2$ & $24-26$ & 25 & 7 & 34,65 & 34,69 & 0,12 \\
14 & 1 & $26-28$ & & 5 & 30 & 30 & 0 \\
15 & 1 & $28-30$ & & 3 & 34,65 & 34,69 & 0,12 \\
16 & 1 & $30+$ & & 7 & 30 & 30 & 0 \\
17 & 1 & $30+$ & 10 & 5 & 10 & 10 & 0 \\
18 & 1 & $30+$ & & 3 & 10 & 10 & 0 \\
\hline & & & & & & \\
\hline \\
\hline
\end{tabular}

Gambar 5. Pengujian Software

Contoh pembuktian perhitungan manual untuk nomor 9 pada tabel 3 dengan terdapat error sebesar $0,02 \%$.

$\begin{array}{ll}P P M & : 45 P P M \\ \triangle P P M & : 7 P P M\end{array}$

Kecepatan Putar Kipas : : 65,3125\%

Derajat keanggotaan PPM pada saat nilainya 45 PPM adalah Low (Representasi Linear Naik) dan Medium (Representasi Linear Turun).

Low $=\left(\frac{b-x}{b-a}\right)=\left(\frac{50-45}{50-40}\right)=0,5$

Medium $=\left(\frac{x-a}{b-a}\right)=\left(\frac{45-40}{50-40}\right)=0,5$

Derajat keanggotaan $\triangle P P M$ pada saat nilainya 7 $P P M$ adalah Medium (Representasi Linear Turun) dan High (Representasi Linear Naik).

Medium $=\left(\frac{b-x}{b-a}\right)=\left(\frac{8-7}{8-6}\right)=0,5$

$H i g h=\left(\frac{x-a}{b-a}\right)=\left(\frac{7-6}{8-6}\right)=0,5$

Dengan merujuk pada tabel sebelumnya dan menggunakan operator MAX yakni dengan mengambil nilai yang maksimum atau lebih besar, maka didapatkan aturan sebagai berikut:

1. Jika PPM Low $(0,5)$, dan $\triangle P P M$ Medium $(0,5)$, maka kecepatan putar kipas Medium $(0,5)$.

2. Jika PPM Low $(0,5)$, dan $\triangle P P M$ High $(0,5)$, maka kecepatan putar kipas Medium $(0,5)$.

3. Jika PPM Medium $(0,5)$, dan $\triangle P P M$ Medium $(0,5)$, maka kecepatan putar kipas Medium $(0,5)$.

4. Jika PPM Medium $(0,5)$, dan $\triangle P P M$ High $(0,5)$, maka kecepatan putar kipas High $(0,5)$.

Berdasarkan 4 aturan diatas, diambil kesimpulan aturan menggunakan operator MIN atau mengambil nilai minimum sehingga didapatkan kesimpulan aturan kecepatan putar 
kipas sebagai berikut: "Maka kecepatan putar kipas adalah Medium $(0,5)$ dan High $(0,5)$ "

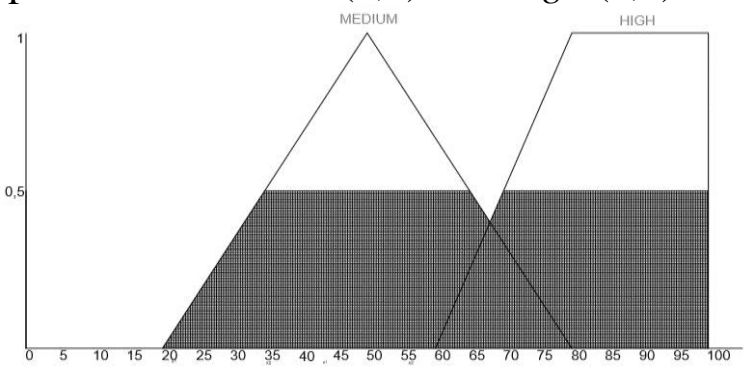

Gambar 5. Mem. Medium $(0,5) \& \operatorname{High}(0,5)$

Berdasarkan hasil perhitungan manual dari kecepatan putar kipas pada saat $P P M$-nya 45 $P P M$ dan $\triangle P P M$-nya $7 P P M$ yang terdapat pada tabel 5 adalah sebesar $65,31 \%$. Artinya terdapat error sebesar $0,02 \%$ pada proses fuzzyfikasi di program arduino.

\section{KESIMPULAN DAN SARAN \\ Kesimpulan}

1. Hardware alat dibuat sesuai dengan rancangan desain mekanik alat. Software diprogram dengan program utama dan program komputasi untuk fuzzy logic yang diinterface-kan ke program utamanya.

2. Pada pengujian tegangan pada setiap PPM, kenaikan tegangan output sensor MQ2 linear tetapi tidak konstan. Rata-rata kenaikan tegangan output-nya mencapai 0,04 VDC jika sistem baru benar-benar diaktifkan. Rata-rata kenaikan tegangan output-nya mencapai 0,035 VDC jika sistem benar-benar dalam keadaan steady state.

3. Pada pengujian fuzzyfikasi, didapatkan ketika kadar PPM naik, maka kecepatan putar kipas akan naik, ketika kadar $P P M$ turun, maka kecepatan putar kipas akan turun.

4. Sistem akan memberikan sinyal bahaya berupa aktifnya buzzer jika dan hanya jika kadar kepekatan asap mencapai 80 PPM .

5. Kecepatan putar kipas yang ditampilkan sistem oleh $L C D$ menunjukkan nilai desimal yang bulat, sehingga terdapat perbedaan apabila dibandingkan dengan perhitungan manual. Pada sistem oleh $L C D$ terbaca 34,65 sedangkan pada perhitungan terbaca 34,6875. Artinya terdapat error sebesar $0,12 \%$.

6. Rata-rata error pada pengujian fuzzyfikasi naik dan turun masing-masing terdapat pada angka $0,04 \%$ dan $0,08 \%$.

\section{Saran}

1. Peneliti menyarankan untuk melakukan pengujian efisiensi alat pada penelitian ini.

2. Peneliti menyarankan untuk memperhatikan kondisi lingkungan sekitar terhadap sensor.

3. Peneliti menghimbau kepada seluruh masyarakat umum untuk mengenali lebih baik lagi bahaya dari rokok.

4. Peneliti menghimbau kepada seluruh masyarakat umum yang menjadi perokok aktif untuk segera sadar dan berhenti merokok.

5. Peneliti mengharapkan kritik dan saran yang membangun dari para pembaca agar memotivasi peneliti untuk terus giat melakukan penelitian yang lebih baik lagi.

\section{DAFTAR PUSTAKA}

Anindya, C., Festiawan, F.B., Fuada, S., \& Shofiyulloh, D. (2013). Implementasi Microcontroller Sebagai Detektor Asap Rokok Sederhana. Seminar Nasional Teknologi Informasi 2013, 1:1-7.

Kusumadewi, Sri dan Hari Purnomo. (2007). Aplikasi Logika Fuzzy untuk Pendukung Keputusan Cetakan ke-4. Yogyakarta: Graha Ilmu.

Kuswadi, Son. (2007). Kendali Cerdas, Teori dan Aplikasi Praktisnya. Yogyakarta: C. V. Andi Offset.

Pandjaitan, Lanny. W. (2007). Dasar-dasar Komputasi Cerdas. Yogyakarta: C. V. Andi Offset.

Sitepoe, Mangku. (2000). Kekhususan Rokok Indonesia. Jakarta: Grasindo.

Talumewo, R.F., Sompie, S.R.U.A., Mamahit, D.J., \& Narasiang, B.S. (2012). Rancang Bangun Alat Pengkondisi Udara Pada Ruangan Menggunakan Sensor $\mathrm{CO}$ dan Temperatur. Jurnal Teknik Elektro, FTUNSRAT, 1:1-6.

Utomo, B.T.W., Saputro, D.S. (2016). Simulasi Sistem Pendeteksi Polusi Ruangan Menggunakan Sensor Asap dengan Pemberitahuan Melalui SMS ( Short Message Service ) dan Alarm Berbasis Arduino. Jurnal Ilmiah Teknologi dan Informasia ASIA (JITIKA), 10:56-6 